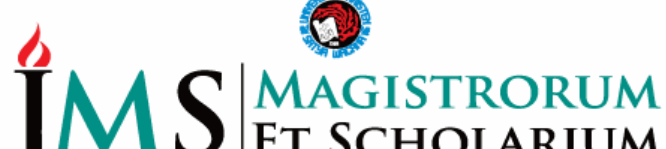 \\ MUS É SCHOLRRUM
}

P-ISSN: 2722-9270 ejournal.uksw.edu/jms

\section{Pendidikan Dan Penyuluhan Kepada Masyarakat Desa Kalikurmo Kecamatan Bringin Kabupaten Semarang}

\author{
Hartati Soetjipto \\ Cucun Alep Riyanto \\ Teresa Febriyanti \\ Yoga Andika Putra \\ Mitra Krisdayanti \\ Laili Nurrohmah
}

Fakultas Sains dan Matematika, Universitas Kristen Satya Wacana; hartati.sucipto@staff.uksw.edu.

A R T I C L E I N F O

Article history:

Received 12 Juli 2020

Revised 30 Juli 2020

Accepted 25 Agustus 2020

Key words:

Desa Kalikurmo; Penyuluhan;

Bimbingan Pengajaran

\begin{abstract}
A B S T R A C T
This Community Service activity is aimed at improving the quality of teaching and learning of Kalkurmo Village Elementary School children, Beringin District, Semarang Regency in the fields of Science and Mathematics. Kalikurmo Village has human resources who have low educational backgrounds, so that its residents have minimal insight and are less developed. This caused us to be moved in providing counseling to the residents of Kalikurmo Village, which if it could help add to their insight and knowledge. Activities carried out in the form of assisting classroom teaching and tutoring outside class hours. Elementary school student are helped in deepening science and mathematics material by this activity.
\end{abstract}

\begin{abstract}
A B S T R A K
Kegiatan Pengabdian kepada Masyarakat ini ditujukan untuk peningkatan kualitas pengajaran dan pembelajaran anak-anak SD Desa Kalikurmo, Kecamatan Beringin, Kabupaten Semarang dalam bidang IPA dan matematika. Desa Kalikurmo memiliki sumber daya manusia yang memiliki latar pendidikan yang rendah, sehingga para warganya memiliki wawasan yang minim dan kurang berkembang. Hal ini menyebabkan kami tergerak dalam memberikan penyuluhan kepada warga Desa Kalikurmo yang sekiranya bisa membantu menambah wawasan dan pengetahuan mereka. Kegiatan dilaksanakan dalam bentuk membantu pengajaran di kelas dan bimbingan belajar di luar jam pelajaran. Anak-anak sekolah tingkat SD terbantu dalam pendalaman materi IPA dan Matematika dengan adanya kegiatan
\end{abstract} ini.

\section{PENDAHULUAN}

Pada masa pemerintahan Presiden Susilo Bambang Yudhoyono, diterbitkan Inpres Nomor 3 Tahun 2010 yang berisi program pembangunan yang pro-rakyat 
dengan prioritas penanggulangan kemiskinan berbasis keluarga dengan menjalankan program pemberdayaan masyarakat serta usaha mikro. Hal ini dilakukan karena melihat indeks pembangunan manusia di Indonesia masih jauh dari kata ideal, sehingga diperlukan berbagai upaya untuk meningkatkannya. Untuk mencapai tujuan pembangunan millennium, perlu dengan mengedepankan delapan sasaran dan tujuan pembangunan milenium (Millenium Development Goals-MDGs) utamanya pengentasan kemiskinan untuk berkeadilan, yaitu pembangunan pro-rakyat, keadilan untuk semua program pembangunan yang berkeadilan dan pro-rakyat yaitu keadilan untuk semua terlebih keadilan untuk anak, perempuan, ketenagakerjaan, hukum, serta kelompok miskin dan termarginalkan (Devi,2013).

Sesuai dengan Tri Dharma perguruan tinggi yang ketiga yaitu pengabdian kepada masyarakat, maka tanggung jawab seorang mahasiswa setelah menyelesaikan tugas belajar di kampus adalah mentransfer, mentransformasikan, dan mengaplikasikan ilmu pengetahuan dari dalam kampus kepada masyarakat. Sebagai mahasiswa dari perguruan tinggi yang berbasis program studi sains, bentuk pengabdian kami kepada masyarakat adalah berperan serta dalam usaha memajukan masyarakat sebagai sumber daya manusia Indonesia melalui usaha peningkatan mutu pendidikan. Salah satu wadah untuk mengaplikasikan program pengabdian ini adalah program Praktik Kerja Lapangan (PKL).

a. Desa Kalikurmo adalah salah satu desa yang terletak di Kecamatan Bringin, Kabupaten Semarang yang menjadi sasaran utama kami dalam melakukan PKL. Desa Kalikurmo memiliki sumber daya manusia yang memiliki latar pendidikan yang rendah, sehingga para warganya memiliki wawasan yang minim dan kurang berkembang. Hal ini menyebabkan kami tergerak dalam memberikan penyuluhan kepada warga Desa Kalikurmo yang sekiranya bisa membantu menambah wawasan dan pengetahuan mereka. Pada zaman era globalisasi ini kemajuan Teknologi sangatlah pesat. Semakin banyaknya aplikasi dan game online yang dengan mudahnya bisa diakses mengakibatkan kebanyakan orang tidak lagi mengenal waktu ketika sudah bermain gadget. Sejak masih kecil sudah banyak anak-anak yang sudah diijinkan oleh orang tuanya boleh bermain gadget. Hal ini dapat mempengaruhi minat dan motivasi anak dalam belajar karena semakin canggihnya teknologi dapat mengakses game maupun aplikasi lain yang lebih menarik minat anak-anak dibanding belajar. Oleh karena itu, salah satu program yang akan kami jalankan adalah pengajaran. Untuk membantu anak-anak di Desa Kalikurmo khususnya yang masih SD agar lebih memperhatikan pembelajaran untuk pendidikan mereka. Tujuan kegiatan ini adalah dengan adanya bimbingan belajar bagi anak-anak di Desa Kalikurmo diharapkan dapat meningkatkan semangat dan motivasi belajar anak-anak tersebut. Kegiatan penyuluhan yang berbasis kearifan lokal dapat menambah pengetahuan dan wawasan masyarakat di Desa Kalikurmo.

\section{Analisis Situasi dan Kondisi Wilayah}

Desa Kalikurmo merupakan desa kecil yang terletak di perbatasan antara Kabupaten Grobogan dan Kabupaten Semarang. Desa Kalikurmo terdiri dari 5 Dusun meliputi: Krajan, Pungkruk, Getasan, Sengkrik, dan Gedad. Desa Kalikurmo 
memiliki luas \pm 322 ha dengan luas pemukiman sekitar 95 ha, populasi penduduknya mencapai 2500 jiwa. Desa Kalikurmo berjarak $\pm 20 \mathrm{~km}$ dari Kota Salatiga via Jl. Salatiga- Kedungjati.

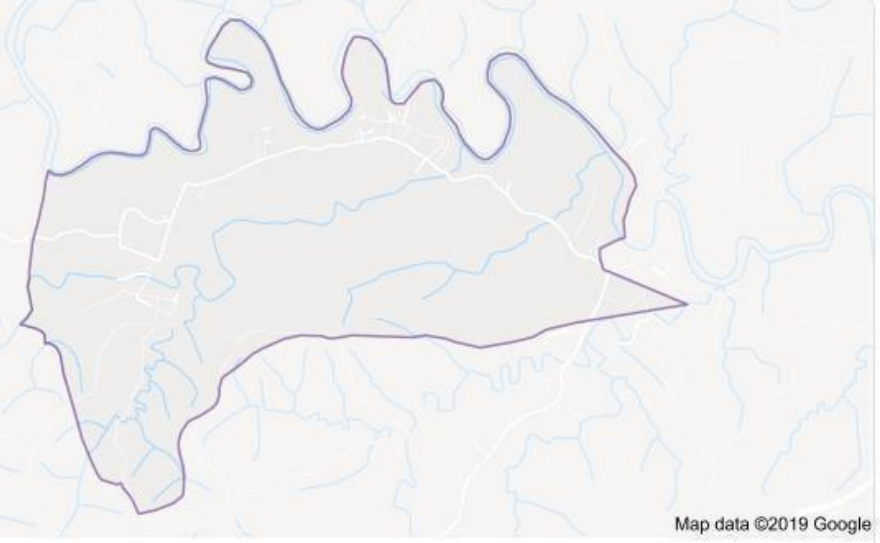

Kalikurmo

Bringin, Semarang, Central Java

Gambar 1. Peta Desa Kalikurmo

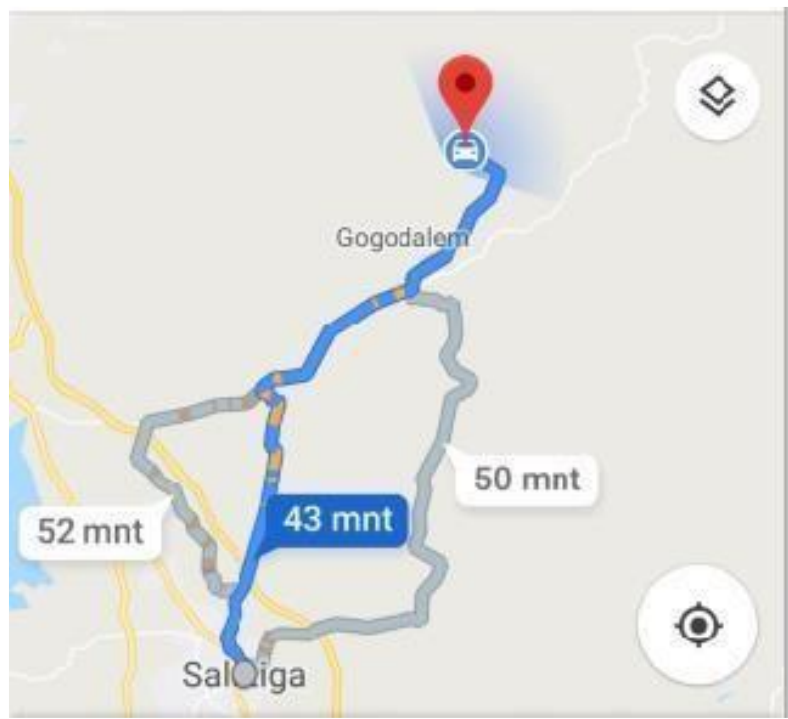

Gambar 2. Jarak Salatiga-Desa Kalikurmo

\section{Kondisi dan Permasalahan Masyarakat}

SDM maupun SDA merupakan faktor yang berperan penting untuk kemajuan di Desa Kalikurmo. Sumber daya manusia di Desa Kalikurmo untuk pendidikan hanya mencapai jenjang SMA. Dengan kenyataan ini berdampak pada kesadaran warga Desa Kalikurmo akan kesehatan, lingkungan, dan kewirausahaan yang masih sangat kurang. Hal ini dapat dilihat dari tingkat perekonomian warga Desa Kalikurmo yang berada pada tingkat menengah ke bawah. Oleh karena itu, diadakan penyuluhan mengenai aspek kesehatan dan lingkungan maupun kewirausahaan untuk 
menambah pengetahuan mereka mengenai aspek-aspek tersebut. Disamping itu banyak anak-anak di Desa Kalikurmo yang masih duduk di sekolah dasar namun memiliki minat yang rendah dalam belajar. Peningkatan kualitas sumber daya manusia sangat diperlukan sebagai pendukung meningkatnya sumber daya alam. Sumber daya manusia yang masih mudah dibentuk sejak dini, sehingga perlunya membentuk dan memotivasi anak-anak untuk menggali potensi dan pengetahuan dengan belajar. Banyak anak di Desa Kalikurmo hanya memanfaatkan smartphone untuk hiburan semata. Hal ini mengakibatkan para orang tua menjadi semakin cemas akan prestasi putra putri mereka di dunia pendidikan. Tujuan dari kegiatan pengajaran anak usia 7-13 tahun ini adalah membantu anak-anak di Desa Kalikurmo dalam mengajarkan tugas dan PR serta memberikan bekal moral ataupun kebiasaankebiasaan baik yang dapat diterapkan dalam kehidupan sehari-hari dan juga dapat meningkatkan SDM yang ada khususnya pada kalangan anak-anak.

Disamping itu peningkatan SDM akan sangat berpengaruh terhadap kesejahteraan masyarakat Desa Kalikurmo. Kesejahteraan dan pendapatan merupakan dua hal yang selalu beriringan dan terikat satu dengan lainnya. Dalam meningkatkan nilai jual hasil tani diperlukannya usaha-usaha dalam pengelolaan hasil pertanian dan juga limbah yang tidak dimanfaatkan. Sehingga untuk mendukung dalam peningkatan nilai jual diperlukan adanya suatu sistem untuk pemasaran. Sistem pemasaran produk tidak hanya dilakukan secara offline saja namun juga secara online dengan e-commerce yang sekarang lebih digemari oleh konsumen. Penjualan produk secara online (melalui internet) sudah banyak dimanfaatkan sebagai media aktivitas bisnis terutama karena kontribusinya terhadap efisiensi. Diharapkan melalui kegiatan ini, masyarakat Desa Kalikurmo tidak hanya melakukan penjualan melalui offline saja namun juga melalui online dengan $e$ commerce yang sekarang lebih digemari oleh konsumen. Dengan mengenalkan strategi pemasaran berbasis e-commerce akan menambah konsumen dari luar.

\section{METODE PELAKSANAAN}

\section{Pelaksanaan Kegiatan}

\section{Tempat dan Waktu Pelaksanaan}

Pengabdian masyarakat dilaksanakan di Desa Kalikurmo selama 12 hari kerja, sejak tanggal 2 Maret 2020 hingga 17 Maret 2020. Desa Kalikurmo terletak di Kecamatan Bringin, Kabupaten Semarang.

\section{Pendidikan}

Kegiatan ini dilakukan dalam rangka meningkatkan motivasi belajar dari anak-anak Desa Kalikurmo. Bimbingan belajar dilaksanakan dalam 2 metode, metode pertama dilakukan di Dusun Gedad dalam bentuk pengajaran tambahan di luar jam sekolah dan metode yang kedua dilakukan melalui metode pengajaran di SDN Kalikurmo dan MIN 6 Semarang. 


\section{Penyuluhan}

Dalam rangka menambah pengetahuan masyarakat di Desa Kalikurmo agar memiliki wawasan yang lebih luas maka diadakan penyuluhan berbasis kearifan lokal.

\section{HASIL DAN PEMBAHASAN}

\section{Pendidikan}

Desa Kalikurmo Kecamatan Beringin Kabupaten Semarang terdiri dari 5 dusun yaitu Dusun Gedad, Sengkrik, Getasan, Pungruk, dan Krajan. Mayoritas anak-anak di Dusun Gedad menempuh pendidikan di Desa tetangga yaitu di SDN Wiru 1. Sedangkan anak-anak dari ke-empat dusun lainnya menempuh pendidikan di SDN Kalikurmo dan MIN 6 Semarang yang berlokasi di Dusun Krajan. Umumnya anakanak di Desa Kalikurmo ini memiliki motivasi belajar yang kurang dan cenderung lebih senang untuk bermain. Disisi lain anak-anak ini juga banyak menghabiskan waktu dengan bermain gadget. Oleh karena itu, pada kegiatan pengabdian kepada masyarakat ini dilakukan bimbingan belajar guna meningkatkan motivasi belajar dari anak-anak Desa Kalikurmo. Bimbingan belajar dilaksanakan dalam 2 metode, metode pertama dilakukan di Dusun Gedad dalam bentuk pengajaran tambahan Matematika dan IPA di luar jam sekolah dan metode yang kedua dilakukan melalui metode pengajaran untuk matematika di SDN Kalikurmo dan mata pelajaran IPA di MIN 6 Semarang. Untuk metode pertama dilaksanakan setiap seminggu sekali pada hari Jumat pukul 15.00-17.00 WIB di Masjid Dusun Gedad. Dokumentasi bimbingan belajar kepada anak-anak sekolah di luar jam pelajaran ditunjukkan pada Gambar 3.

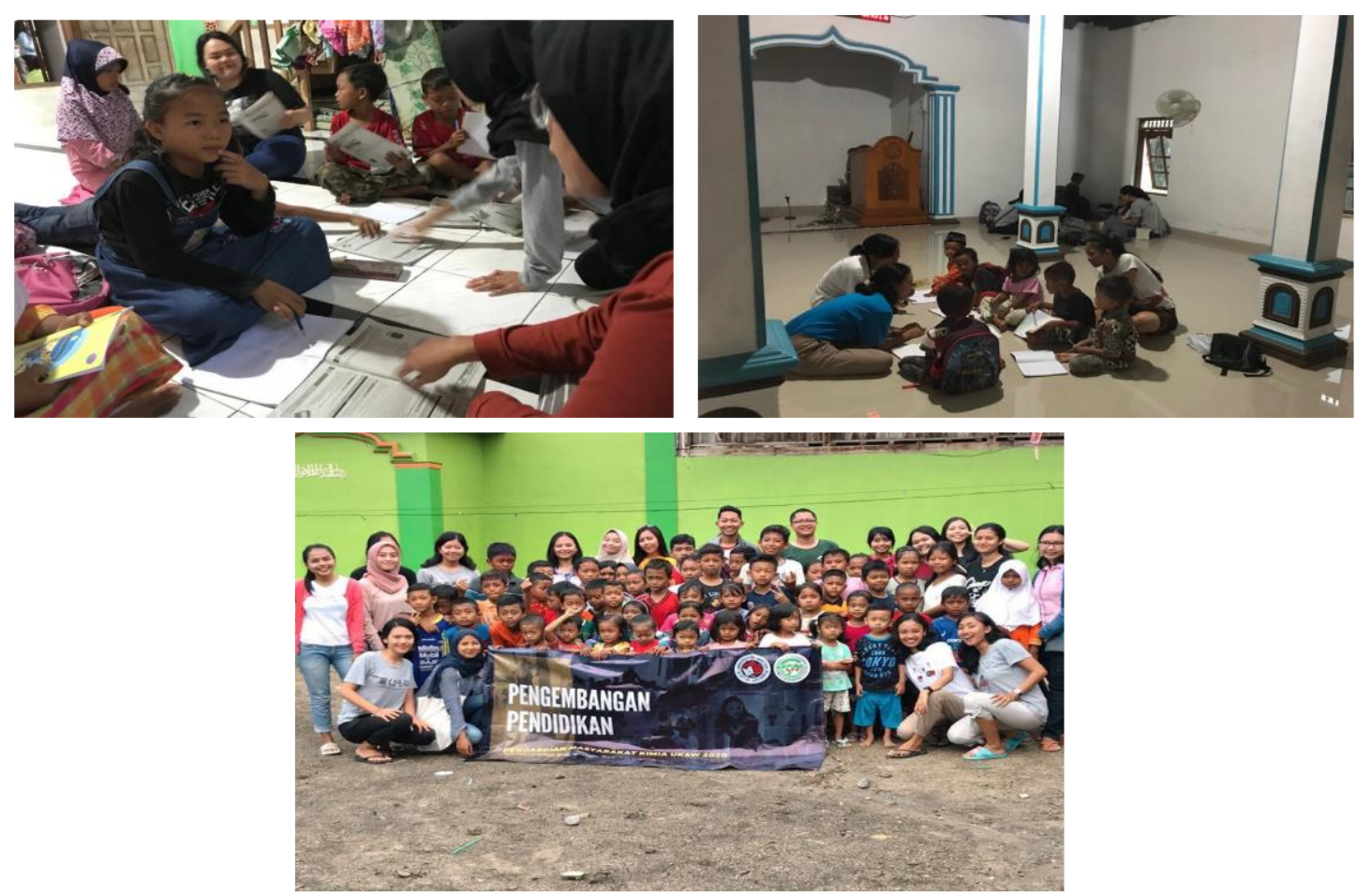

Gambar 3. Kegiatan bimbingan belajar di luar jam pelajaran bagi anak-anak SD Desa Kalikurmo 
Metode kedua adalah melalui pelaksanaan pengajaran intrakurikuler pada jam pelajaran sekolah. metode yang kedua dilaksanakan 2 kali dalam seminggu, pada hari Kamis (09.00-11.00 WIB) dan Jumat (09.00-11.00 WIB) dengan untuk SDN Kalikurmo serta pada hari Selasa (10.30-12.30 WIB) dan Sabtu (07.30-09.30 WIB) untuk MIN 6 Semarang. Peningkatan pengajaran ini dilakukan dengan memperkaya dan mendalami materi IPA dan Matematika bagi peserta didik (Tabel 1). Dokumentasi kegiatan ini ditunjukkan pada Gambar 4.

Tabel 1. Pengajaran di Desa Kalikurmo

\begin{tabular}{llll}
\hline \multicolumn{1}{c}{ Hari/ tgl } & \multicolumn{1}{c}{ Lokasi mengajar } & \multicolumn{1}{c}{ Materi belajar } & \multicolumn{1}{c}{ Sumber Buku } \\
\hline Kamis, 12 Maret 2020 & SDN Kalikurmo & Diangram Batang & ESPS Matematika \\
Jumat, 13 Maret 2020 & SDN Kalikurmo & Pengolahan Data & ESPS Matematika \\
Jumat, 13 Maret 2020 & Dusun Gedad & $\begin{array}{l}\text { Mengidentifikasi } \\
\text { berbagai sumber energi } \\
\text { dan sumber energy }\end{array}$ & ESPS IPA \\
& & alternative dalam & \\
& & kehidupan sehari-hari, & \\
& Bangun Ruang & \\
& Sederhana, KPK dan & \\
& FPB,Komponen & \\
& & Penyusun Campuran, & \\
Sabtu, 14 Maret 2020 & MIN 6 Semarang & Bangun datar & ESPA IPA \\
\hline
\end{tabular}

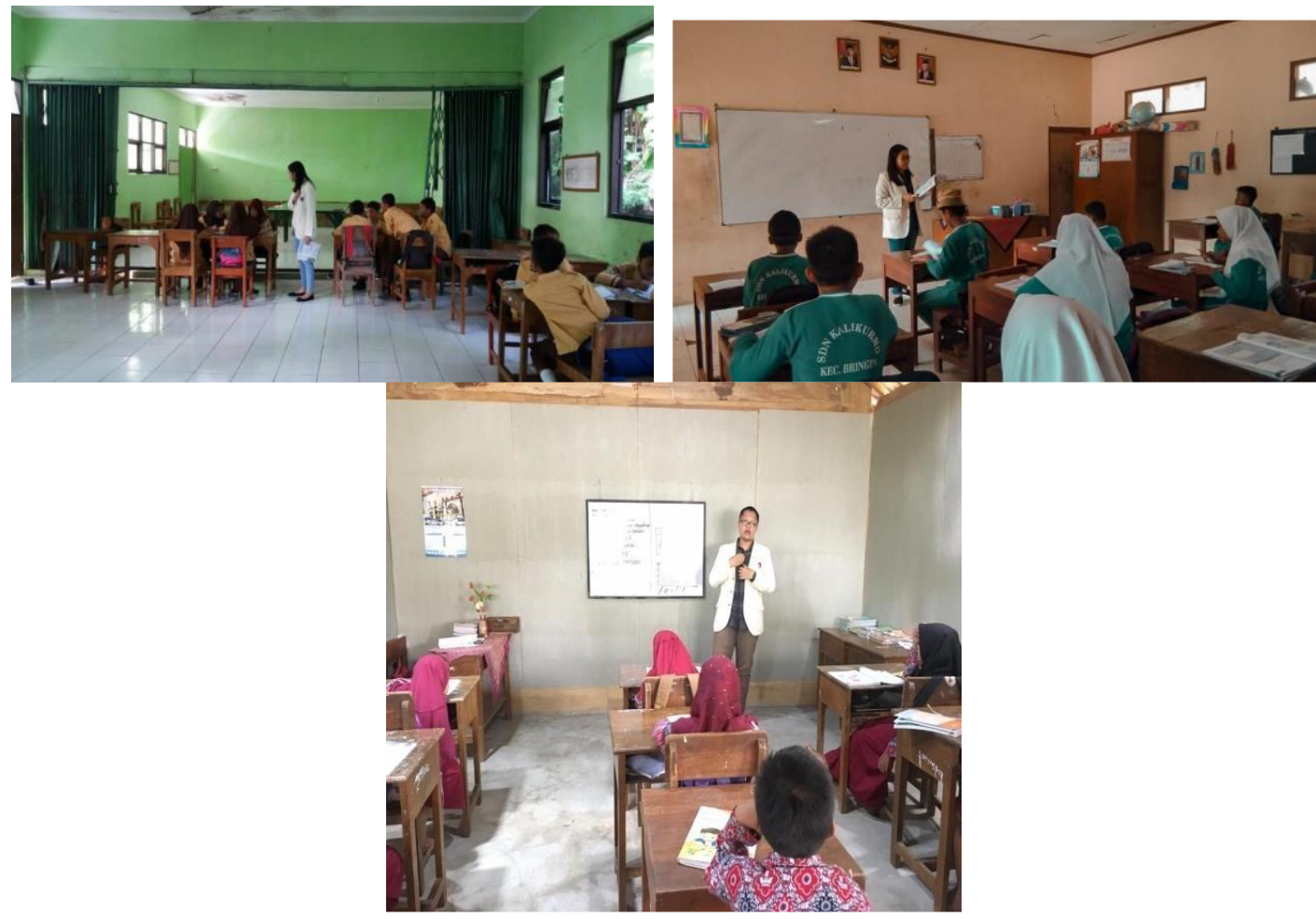

Gambar 4. Kegiatan pengajaran intrakurikuler pada jam pelajaran di SDN Kalikurmo dan MIN 6 Semarang 
Kegiatan membantu pengajaran ini sangat diapresiasi pihak sekolah. Bersama guru-guru, tim kegiatan ini berdiskusi dalam peningkatan pendalaman pembelajaran dan pengayaan materi belajar. Tim ini diberi kesempatan untuk menyampaikan masukan-masukan dalam hal pendalaman dan pengayaan materi. Dokumentasi kebersamaan dengan pihak Sekolah ditunjukkan pada Gambar 5.
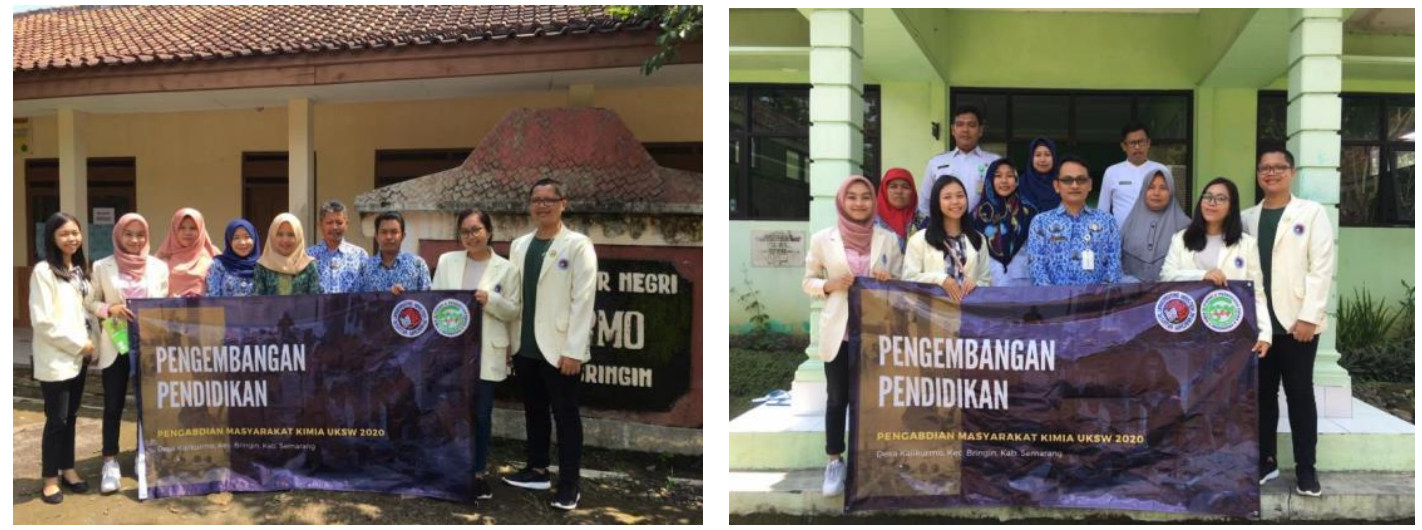

Gambar 5. Bersama pihak sekolah SDN Kalikurmo dan MIN 6 Kabupaten Semarang dalam peningkatan kualitas pembelajaran

\section{Penyuluhan}

Mayoritas masyarakat Desa Kalikurmo berprofesi sebagai petani jagung. Rata-rata masyarakat di desa tersebut memiliki latar belakang pendidikan yang rendah (lulusan SD/SMP) sehingga pola pikir masyarakat belum maju. Untuk menambah pengetahuan masyarakat maka pada PKL ini diadakan penyuluhan berbasis kearifan lokal. Kegiatan penyuluhan diadakan pada hari Selasa, 10 Maret 2020 di Balai Desa Kalikurmo pada pukul 10.00-12.00 WIB. Pada penyuluhan ini disampaikan beberapa materi yang meliputi :

- Pupuk Takakura dengan menggunakan limbah organik rumah tangga untuk mengurangi penggunaan pupuk an-organik.

- Minuman Kesehatan dengan memanfaatkan limbah rambut jagung untuk dijadikan teh yang dapat mengatasi penyakit diabetes, hipertensi, kolesterol, dll.

- E-commerce dengan memberdayakan pemuda di Desa Kalikurmo yang memiliki potensi dalam berwirausaha. 


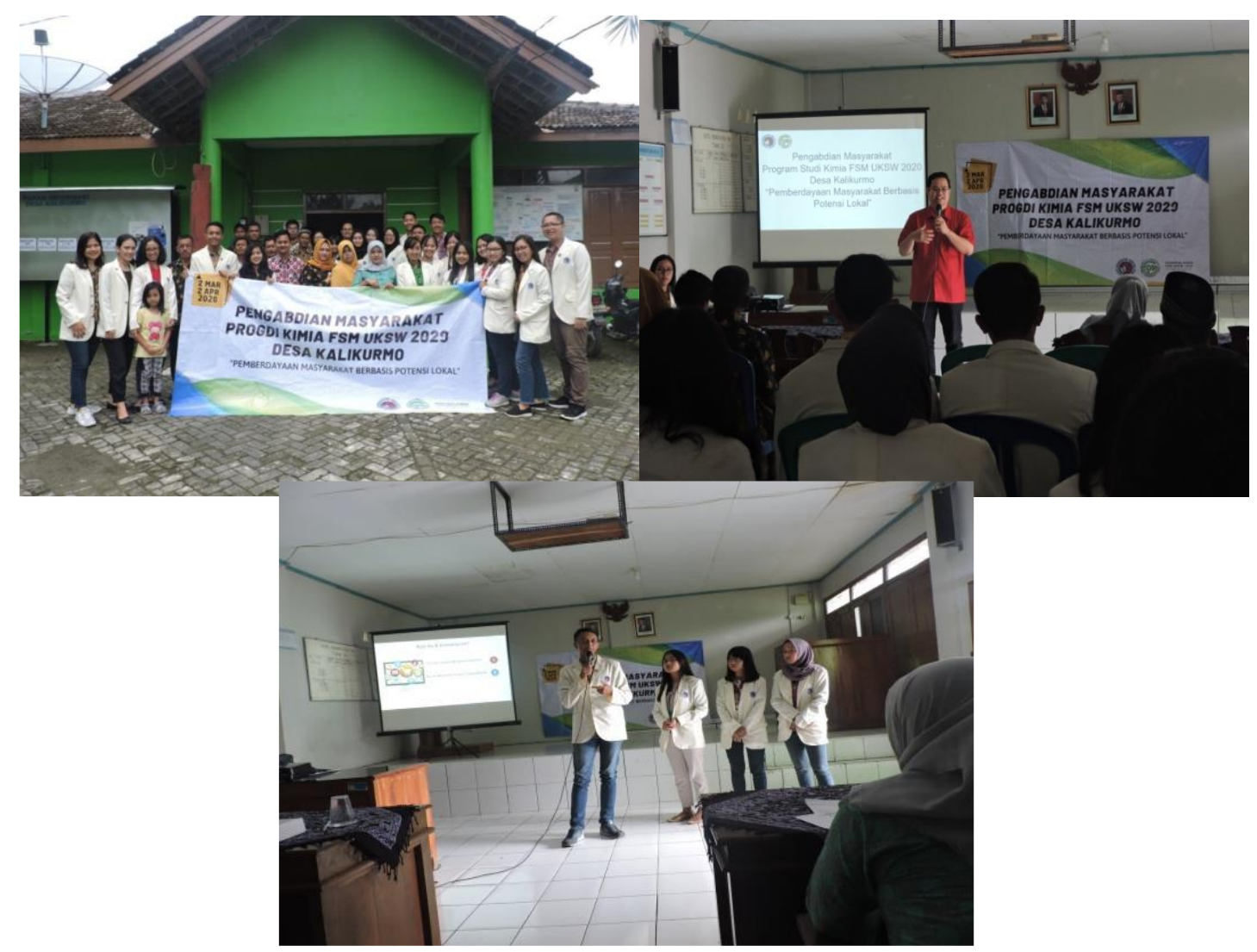

Gambar 6. Kegiatan Penyuluhan bersama warga dan perangkat Desa Kalikurmo

\section{SIMPULAN}

1. Kegiatan bimbingan belajar di Dusun Gedad dilaksanakan setiap seminggu sekali pada hari Jumat pukul 15.00-17.00 WIB di Masjid Dusun Gedad. Kegiatan bimbingan belajar dilaksanakan 2 kali dalam seminggu, pada hari Kamis (09.00-11.00 WIB) dan Jumat (09.00-11.00 WIB) untuk SDN Kalikurmo serta pada hari Selasa (10.30-12.30 WIB) dan Sabtu (07.30-09.30 WIB).

2. Kegiatan penyuluhan diadakan pada hari Selasa, 10 Maret 2020 di Balai Desa Kalikurmo pada pukul 10.00-12.00 WIB. Pada penyuluhan ini disampaikan beberapa materi yang meliputi pupuk takakura, minuman kesehatan, dan $E$ commerce.

\section{DAFTAR PUSTAKA}

Devi, L. V. R. (2013). Upaya Program Pos Pebardayaan keluarga (POSDAYA) Dalam Pengentasan Kemiskinan. JKMP, 1(1), 21-32. 